\title{
Drones to the rescue? Exploring rescue workers' behavioral intention to adopt drones in mountain rescue missions
}

\author{
Patrick Holzmann \\ Department of Innovation Management and Entrepreneurship, \\ University of Klagenfurt, Klagenfurt, Austria \\ Christian Wankmüller \\ Department of Operations, Energy, and Environmental Management, \\ University of Klagenfurt, Klagenfurt, Austria, and \\ Dietfried Globocnik and Erich J. Schwarz \\ Department of Innovation Management and Entrepreneurship, \\ University of Klagenfurt, Klagenfurt, Austria
}

\begin{abstract}
Purpose - Mountaineering and related activities are increasingly becoming popular and are accompanied by an increase in medical incidents. Emergency operations in mountainous terrain are time-critical and often pose major logistical challenges for rescuers. Drones are expected to improve the operational performance of mountain rescuers. However, they are not yet widely used in mountain rescue missions. This paper examines the determinants that drive the behavioral intention of mountain rescuers to adopt drones in rescue missions. Design/methodology/approach - This is a behavioral study that builds upon an extended model of the unified theory of acceptance and use of technology (UTAUT) and investigates the relationship between individual attitudes, perceptions, and intentions for drone adoption. Original survey data of 146 mountain rescuers were analyzed using moderated ordinary least squares (OLS) regression analysis.

Findings - Results indicate that the behavioral intention to use drones in mountain rescue missions is driven by the expected performance gains and facilitating conditions. Favorable supporting conditions and experience with drones further moderate the relationship between performance expectancy and behavioral intention. The effects for effort expectancy, social influence, and demonstrations were not significant.

Practical implications - Rescue organizations and stakeholders are recommended to consider the identified determinants in the implementation of drones in emergency logistics. Drone manufacturers targeting mountain rescue organizations are advised to focus on operational performance, provide sufficient support and training, and promote the gathering of practical experience.

Originality/value - A tailored-model that provides first empirical results on the relevance of personal and environmental factors for the acceptance of drones in emergency logistics is presented.
\end{abstract}

Keywords Drone technology, UAV, Emergency logistics, Unified theory of acceptance and usage of technology, Adoption

Paper type Research paper

(C) Patrick Holzmann, Christian Wankmüller, Dietfried Globocnik and Erich J. Schwarz. Published by Emerald Publishing Limited. This article is published under the Creative Commons Attribution (CC BY 4.0) licence. Anyone may reproduce, distribute, translate and create derivative works of this article (for both commercial and non-commercial purposes), subject to full attribution to the original publication and authors. The full terms of this licence may be seen at http://creativecommons.org/licences/by/4.0/ legalcode

This work was supported by the European Union Fund for regional development and INTERREG V-A Italy Austria 2014-2020 and was carried out while the second author was employed within the INTERREG project START (Smart Test for Alpine Rescue Technology).

Received 27 January 2020 Revised 17 September 2020 4 December 2020 8 February 2021 10 February 2021

Accepted 11 February 2021 
IJPDLM 51,4

\section{2}

\section{Introduction}

Human life is far more important than just getting to the top of a mountain. (Sir Edmund P. Hillary)

In recent years, mountaineering and outdoor activities in mountainous regions have increased heavily as these regions are becoming more easily accessible, even for nonprofessionals (Apollo, 2017). However, with the rising number of people conquering the mountains, medical emergencies have also become more frequent (Mort and Godden, 2011; Muhar et al., 2007; Ciesa et al., 2014). In the European Alps and in North America, the number of rescue missions has steadily increased over several decades (Lischke et al., 2001; Heggie, 2008). This development presents additional challenges for mountain rescuers as responding to emergencies is complicated due to logistics challenges, including heavy terrain and adverse weather conditions. Furthermore, the diversity and complexity of response missions pose major challenges (Yarwood, 2010; Blancher et al., 2018). Infrastructural barriers (Pietsch et al., 2019) can prevent aerial response by helicopters. Thus, the time-consuming ascent of mountain rescuers on foot is the only viable option.

With the available equipment on hand, response teams today often reach their performance limits, putting their own lives at risk to save the lives of others (Shimansky, 2008). Hence, rescue organizations have started to realize that aside from investments into training and command, the adoption of technological innovations can increase response teams' operational performance and extend their scope of action. Among the technological innovations of recent years, such as the RECCO rescue system for radar-based avalanche victim search, unmanned aerial vehicles (UAV) or drones are expected to provide remarkable emergency logistics and operational performance improvements (Mangiaracina et al., 2019; Kakaes et al., 2015; Anbaroğlu, 2019). Drones can traverse areas that are inaccessible for landbased transportation at lower cost and risk compared to traditional means of transport (Kharb, 2015; Škrinjar et al., 2018). In particular, drones can assist in damage assessment, emergency items delivery, and search and rescue (SAR) missions (Hayajneh et al., 2018; Cui et al., 2015; Doherty and Rudol, 2007; Câmara, 2014; Rabta et al., 2018; Kiss Leizer, 2018). Recently, drones have already been used for SAR and disaster mapping, for instance, in the 2015 earthquake in Nepal (Balasingam, 2017). In mountainous regions, drones can be of paramount importance as they can increase the probability to safely reach isolated places even in heavy terrain, which is of particular relevance in SAR of missing people and the provision of urgently-needed medical items. Nonetheless, drone usage for mountain rescue missions is still in its infancy, but lately, leading organizations such as the International Commission for Alpine Rescue (ICAR) have started to promote the technology actively (ICAR, 2019).

Despite these potential benefits, our knowledge of the determinants that facilitate the adoption of drones by mountain rescuers is limited. Behavioral studies that examine the individual expectations and beliefs of mountain rescuers and, ultimately, their intention to adopt drones are missing. Adoption literature posits that technology adoption is driven by personal and institutional factors (Venkatesh et al., 2003; Holzmann et al., 2020). We assume that the individual expectations of the gains in operational performance and the required efforts to use drones are essential. Further, the intention to adopt drones may be shaped by societal influence or the perception of the surrounding conditions. We also assume that individual experiences with drones can influence adoption.

Having a deeper understanding of the drivers of mountain rescuers' intention to adopt drones is of paramount importance to realize the associated performance improvements. We aim at contributing to the discussion by answering the following research question: What factors determine the behavioral intention of mountain rescuers to use drones in rescue missions?

We build upon the unified theory of acceptance and use of technology (UTAUT) (Venkatesh et al., 2003) and analyze data of 146 mountain rescuers. Results indicate that 
expected performance gains, favorable facilitating conditions, and drone experience determine the behavioral intention. Facilitating conditions and experience further moderate the relationship between performance expectations and intention. Thereby, we contribute to the limited body of literature on drone acceptance in emergency logistics and the adoption of live-saving technology. We further broaden the horizon of mountain rescue organizations and drone manufacturers by highlighting which levers are most promising to promote drone usage in mountain rescue operations. Building on this, we further seek to understand how drone manufacturers can facilitate the use of drones among mountain rescuers.

\section{Literature review}

\subsection{Drone assistance in mountain rescue missions}

Recent research found that the use of drones is beneficial in SAR missions and emergency items delivery. In particular, results indicate that drones allow quicker rescue missions (McRae et al., 2019) because they can decrease the time to arrival at the emergency site, increase the total search area, and the area searched per minute (Karaca et al., 2018). Further studies revealed that drone assistance can provide safety benefits for mountain rescue teams in difficult and hazardous terrain (van Tilburg, 2017). Drone imaging can further support route planning (Karak and Abdelghany, 2019).

Existing SAR processes often combine terrestrial and aerial interventions. Aerial support is advantageous because SAR missions usually have to cover large areas, as information about the location is often inaccurate, but this support is often prevented, for example, by adverse weather conditions. Mountain rescuers searching an area by foot are often exposed to external risks such as rock slides. Drone implementation can address these challenges and allows faster and secure searching of the area from a distance. Camera-equipped drones can overfly inaccessible areas and provide a quick, safe, and detailed overview of traces of a missing person (Cacace et al., 2016). In the case of avalanches, drones can complement existing SAR interventions by quickly scanning the area for RECCO signals (Karaca et al., 2018).

Besides increasing the efficiency in mountainous SAR, drones can also facilitate the rapid supply of automated external defibrillators (AED) (Silvagni et al., 2017; Wankmüller et al., 2020). Sudden cardiac arrest (SCA) is very time-sensitive and inevitably leads to death if the response time is too long. First empirical results confirm the practicability of drones for AED delivery (Sanfridsson et al., 2019).

\subsection{Drone adoption in logistics}

In commercial and emergency logistics there is a vivid discussion on drones' performance potentials (Mangiaracina et al., 2019; Kakaes et al., 2015; Anbaroğlu, 2019), but our understanding of the acceptance of drones for logistics applications is vague. Boucher (2016) identifies a pressing need to generate more insights about the public acceptance of drones for delivery applications and presents several boundaries (e.g. privacy, operational benefits) for drone acceptance. The relevance of privacy and safety concerns and functional performance for consumers' attitude toward drone delivery services is confirmed by further research (Ramadan et al., 2017; Khan et al., 2019). Scholars further stress the need for intensified research on human factors that determine adoption and report that drone acceptance differs among user groups. While laypeople fear the violation of their privacy, pilots see the risk of drone accidents that negatively affect adoption (Lidynia et al. (2017).

In emergency logistics, potential performance gains through drone use have been a primary subject of interest (Hayajneh et al., 2018; Cui et al., 2015; Câmara, 2014; Rabta et al., 2018),
Drones to the rescue? 
IJPDLM 51,4

but research remained silent about the drivers of acceptance that support efficient and effective implementation. We contribute to this infant stream by presenting the drivers of adoption and their impact on the behavioral intention of mountain rescuers to adopt drones.

\section{Research model}

The intention to use and the actual usage of new technology have been prominent subjects of scholarly investigations. Among the various theoretical models proposed, the UTAUT (Venkatesh et al., 2003) raised considerable interest as it was empirically demonstrated that UTAUT is able to substantially improve the account of variance explained and thus more adequately predicts the acceptance and use of new technology compared to other models. UTAUT draws on essential elements of previous models, for instance, from the theory of reasoned action (TRA) (Fishbein and Ajzen, 1975), the technology adoption model (TAM) (Davis, 1989; Davis et al., 1989), the theory of planned behavior (TPB) (Ajzen, 1991), and the innovation diffusion theory (IDT) (Moore and Benbasat, 1991) and aims at unifying the prevalent different and fragmented perspectives through comprehensive comparison. TRA draws on social psychology and assumes that the behavioral intention to adopt new technology is influenced by the individual's attitude toward behavior and the prevailing subjective norms. TAM was initially developed to predict the acceptance of information technology with the core measurements perceived usefulness and perceived ease of use. TPB builds on TRA and adds the perceived behavioral control construct. It has been applied successfully to predict the acceptance of different technologies (Mathieson, 1991; Ramadan et al., 2017). IDT is rooted in sociology and includes, among others, relative advantage, ease of use, and visibility.

In their seminal paper, Venkatesh et al. (2003) introduced performance expectancy, effort expectancy, and social influence as the main predictors for the acceptance of new technology. We draw on the UTAUT and IDT and develop a model that considers the research context's novelty and particularities. We assume that potential gains in operational performance are a strong driver for the behavioral intention to adopt drones since saving lives is the primary objective of mountain rescuers. We also believe that the easier the mountain rescuers perceive the use of drones, the higher the intention to adopt. Mountain rescuers rely on and trust each other. Therefore, we assume that social factors such as the opinion of important others are relevant. Drawing on recent literature (Venkatesh et al., 2012; Holzmann et al., 2020), we further assume that favorably perceived facilitating conditions can foster adoption intention. Due to drones' novelty in the context of mountain rescue missions, we further expect that drone experience is essential. We assume that facilitating conditions and experience each moderate the performance expectancy-intention relationship and effort expectancyintention relationship. We also controlled for the effects of technological anxiety and attitude toward using technology, job tenure in years, gender, and working hours per month (Figure 1).

\subsection{Performance expectancy}

Performance expectancy (PE) is defined as the degree of an individual's belief that using the technology will enhance the individual job performance (Venkatesh et al., 2003). PE is rooted in TAM's perceived usefulness (Davis, 1989; Davis et al., 1989) and IDT's (Moore and Benbasat, 1991) relative advantage constructs and assumes that individuals strive to increase their performance through technology usage. Recent studies confirm that high PE positively affects new technology adoption decisions in emergency scenarios (Kim and Chung, 2019; Hermanns, 2013; Chen and Lin, 2019). For the purpose of this study, we define $\mathrm{PE}$ as the belief of mountain rescuers that using drones will lead to operational performance 


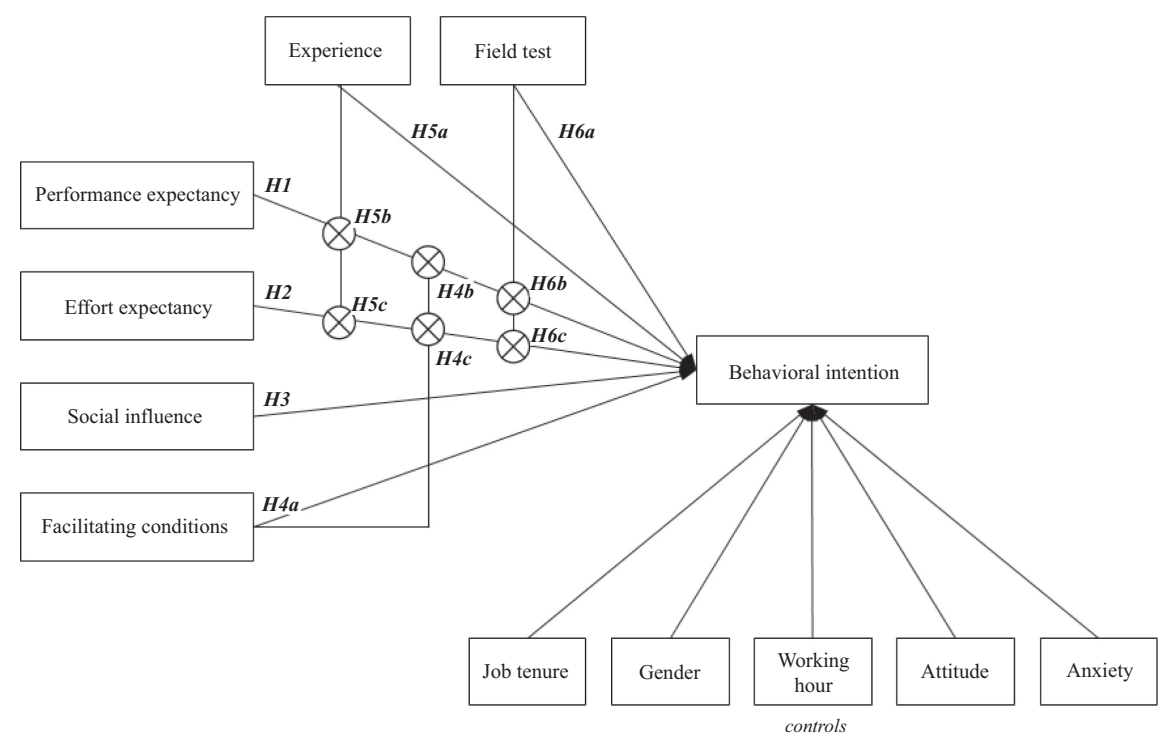

Drones to the rescue?

385

gains. Mountain rescuers aim at saving the lives of others and regularly put their own lives at risk. Efficiency and efficacy of operations are crucial as mistakes often have fatal consequences. Drones promise to provide important operational performance gains as they are, for instance, able to accelerate SAR missions and the urgent delivery of emergency supplies, e.g. by shortening the time to arrival and expanding the search area. Thus, they can also increase the safety of mountain rescuers. We propose:

H1. Performance expectancy positively influences the behavioral intention to use drones.

\subsection{Effort expectancy}

Effort expectancy (EE) refers to the degree of ease that an individual associates with using a specific technology (Venkatesh et al., 2003). EE draws on constructs such as TAM's (Davis, 1989; Davis et al., 1989) perceived ease of use and IDT's (Moore and Benbasat, 1991) ease of use. Venkatesh et al. (2003) theorize that the easier and clearer the use of technology is perceived, the higher the behavioral intention (BI) to use the technology. Emergency logistics studies found that ease of use is a determining factor for adopting novel wearable location systems (Kwee-Meier et al., 2016) and the adoption of drones (Hermanns, 2013). We define EE as a mountain rescuer's belief about the perceived ease of using drones, reflecting the extent to which they feel comfortable using drones in response missions. Mountain rescue operations are risky and dangerous with potentially serious negative consequences. Thus, mountain rescuers must be comfortable using supportive technologies. A high effort required to master technology may outweigh its potential performance benefits and result in the technology not being used (Davis, 1989). Drones and their control can increase the complexity of rescue operations, and mountain rescuers are often volunteers that can devote only limited time to mastering new technologies. We, thus, suggest that the easier the use of drones is perceived to be, the higher their acceptance and propose:

H2. Expectancy of low effort required positively influences the behavioral intention to use drones. 
IJPDLM 51,4

386

\subsection{Social influence}

Social influence (SI) is theorized as the degree to which an individual perceives that important others believe that they should use a technology (Venkatesh et al., 2003). SI is referred to as subjective norm in TRA (Fishbein and Ajzen, 1975), TAM/TAM2 (Davis, 1989; Davis et al., 1989) and TPB (Ajzen, 1991), in IDT (Moore and Benbasat, 1991) it is represented as image. SI is theorized to positively influence BI (Venkatesh et al., 2003), which is also confirmed in the context of security-enhancing technology and drones (Kwee-Meier et al., 2016; Sun et al., 2013; Kim and Chung, 2019). For the purpose of this study, SI refers to how an individual perceives the opinion of important others toward drone usage in mountain rescue missions. Mountain rescuers work in teams that are characterized by comradery, mutual trust, and shared values among team members. However, mountain rescue organizations are also characterized by an inherent hierarchy. Experienced rescuers are respected and trusted and can thus serve as influential role models. If the opinion of important others on drones is positive, it will increase technology acceptance. Consequently, we propose:

H3. Social influence positively influences the behavioral intention to use drones.

\subsection{Facilitating conditions}

Facilitating conditions $(\mathrm{FC})$ refer to the degree to which an individual believes that there is a supporting organizational and technical infrastructure that eases adoption (Venkatesh $e$ al., 2003) and are theorized to drive BI (Venkatesh et al., 2012). Empirical evidence confirms that a favorable perception of FC positively affects the BI to adopt new technology (Halassi et al., 2019; Kapser and Abdelrahman, 2020). We define FC as an individual's perception of the supportiveness of the organizational and technical infrastructure provided by the mountain rescue organization. Drones are new in mountain rescue and require new specific capabilities that are different from those required for traditional response processes. We assume that rescuers are more willing to adopt drones if they expect that the rescue organization will provide access to expertise, specific training, and infrastructure that eases adoption. Thus, we assume that rescuers' belief about the existence of a supportive environment positively affects their BI to use drones and suggest:

$H 4 a$. Facilitating conditions positively influence the behavioral intention to use drones.

Recent research calls for further clarification of the relationships between FC, PE and EE (Nordhoff et al., 2020). Taking a person-context interaction perspective, we propose that the relevance of the $\mathrm{PE}$ and $\mathrm{EE}$ for building the $\mathrm{BI}$ to adopt drones depends upon the $\mathrm{FC}$. The motivating effect of individual $\mathrm{PE}$ on $\mathrm{BI}$ is supposed to be stronger when $\mathrm{FC}$ are more favorable, e.g. if the drone equipment is always ready for use and access to troubleshooting assistance during drone missions is provided. In favorable contexts, rescuers will perceive it as more likely to achieve personal productivity gains in their rescue mission and thereby more likely intent to adopt the technology. In contrast, the motivating effect of perceived individual PE on the BI to adopt drones will be weakened if rescuers perceive themselves to be in an unfavorable organizational context, e.g. no assistance or technical support. Such a context might make it more difficult to achieve personal productivity gains and thereby hamper the impact of $\mathrm{PE}$ on $\mathrm{BI}$ to adopt drones.

Similarly, we expect that the FC moderates the EE-BI relationship. The motivating effect of requiring little effort to master the use of drones in rescue missions on the $\mathrm{BI}$ is supposed to be stronger for rescuers in an organizational context from which proper training opportunities and the provision of easy-to-use drone equipment are expected. In contrast, the motivating effect of perceiving low personal effort on the BI will be lower when the rescuer believes that the organizational context lacks support for learning how to use drones or might even impose organizational hurdles that need to be overcome. Thus, we propose: 
H4b. The positive relationship between performance expectancy and behavioral intention is stronger when facilitating conditions are perceived as favorable.

H4c. The positive relationship between effort expectancy and behavioral intention is stronger when facilitating conditions are perceived as favorable.

\subsection{Experience}

IDT maintains that the provision of individual experience affects the decision to adopt novel technology (Rogers, 2010; Ajzen and Fishbein, 2005). EXP is theorized as a direct reflection that results from an individual's interaction with the technology in question (Hamilton and Thompson, 2007). Technologies that can be tried on are more likely to be adopted (Rogers, 2010). EXP in this study refers to the experience of having flown a drone. Today, drones have not been constantly used in mountain rescue missions, thus, many mountain rescuers are unfamiliar with the technology and have limited knowledge about what efforts and performance to expect. This uncertainty may negatively affect the intention to adopt (Liu et al., 2020; Rogers, 2010). On the other hand, we assume that mountain rescuers with drone experience have a higher BI and suggest:

$H 5 a$. Experience with drones positively influences the behavioral intention to use drones.

We believe that EXP allows assessing drones' potential performance gains in mountain rescue missions more accurately. We expect that the motivating effect of $\mathrm{PE}$ on $\mathrm{BI}$ will be stronger for mountain rescuers with drone experience. In contrast, we expect that due to the novelty of the technology in this context, the motivating effect of $\mathrm{PE}$ on $\mathrm{BI}$ will be weaker for mountain rescuers without drone experience.

Further, and in line with the theoretical assumptions, we expect that EXP will moderate the effects of EE on BI (Venkatesh et al., 2003). EXP enables a more accurate assessment of the required efforts to use drones during response missions. EXP can reduce the associated uncertainties and enhance the perceived ability to control and master the new technology (Subramaniam et al., 2012). Thus, we assume that the effect of EE on BI will be stronger for mountain rescuers with drone experience and weaker for those without. Consequently, we propose:

H5b. The positive relationship between performance expectancy and behavioral intention is stronger (weaker) for mountain rescuers with (without) drone experience.

H5c. The positive relationship between effort expectancy and behavioral intention is stronger (weaker) for mountain rescuers with (without) drone experience.

\subsection{Field test}

Observability is a key attribute in IDT and is defined as the degree to which the results and benefits of an innovation are visible (Rogers, 2010). Or, put differently, the degree to which others who successfully apply the innovation can be observed (Plouffe et al., 2001). Observability in this study was achieved through field tests (FT) that aimed at demonstrating the benefits of drones in mountain rescue missions. Drones are new in mountain rescue and demonstrations are an effective means as they enable participants to observe and assess the technological advantages. Increased visibility and exposure can also reduce uncertainties (Baer et al., 1977). FT are found to enhance the knowledge and capabilities of rescuers and thus the overall quality of response (Schaafstal et al., 2001). FT of drones help to gather more insights on their effectiveness to support SAR and to save lives more efficiently. We expect that FT positively influence $\mathrm{BI}$ and propose: 
IJPDLM

51,4

388

H6a. Field test participation positively influences the behavioral intention to use drones.

We assume that FT can demonstrate the potential performance gains of drones in mountain rescue missions. Thus, we expect that the motivating effect of $\mathrm{PE}$ on $\mathrm{BI}$ will be stronger for mountain rescuers who participated in FT. In contrast, we expect that the motivating effect of $\mathrm{PE}$ on BI will be weaker for mountain rescuers without FT participation.

We further expect that FT will moderate the relationship between EE and BI. Through observation, the effort required to use drones can be estimated more realistically. Thus, uncertainties can be reduced and the perceived ability to control and master drones can be enhanced through FT participation. Consequently, we assume that the effect of EE on BI will be stronger for mountain rescuers who participated in FT and weaker for those who did not and suggest:

H6b. The positive relationship between performance expectancy and behavioral intention is stronger (weaker) for mountain rescuers with (without) field test participation.

H6c. The positive relationship between effort expectancy and behavioral intention is stronger (weaker) for mountain rescuers with (without) field test participation.

\section{Methods}

\subsection{Data collection}

The study was part of the INTERREG project START (Smart Test for Alpine Rescue Technology) in the Alps-region, including Tyrol, South Tyrol, and Carinthia. One objective was to identify, evaluate, and implement innovative technology that increases the performance of rescuers in challenging mountain rescue missions (Bergrettung Tirol, 2019). Drones were identified as a promising technology in this regard.

Since some of the hypotheses explore the relevance of observations, field tests that comprised the delivery of AEDs by drones using parachute systems, SAR with thermographic camera equipped drones, and long-distance drone flights were organized between September and October 2019. Besides the field tests, an emergency response training exercise took place in September 2019. The authors participated in each event and collected the data from the participants on-site using a paper-based questionnaire. To capture data from rescuers that did not participate in the tests, an online version of the survey was distributed among a control group. We contacted high-ranking functionaries within the mountain rescue organizations who agreed to distribute the questionnaire among their members via their internal e-mailing list. Due to potential self-selection bias, the sample might not be fully random. Thus, we tested potential nonresponse bias by comparing the answers of the early and late quartile of respondents. Results demonstrate that there are no significant differences.

\subsection{Sample and methodology}

At the time of the study, 5542 mountain rescuers were active in the project region (Tyrol: 3727; South Tyrol: 1010; Carinthia: 805). Drawing on statistical power analysis (Cohen, 1992), the required sample size to detect medium effect sizes of $\geq 0.15$ when considering a $5 \%$ probability of error, the commonly used level of statistical power of $80 \%$, and 13 predictors (the regression model with the highest number of predictors) of the dependent variable was calculated as of at least 131 required cases.

Data were collected from the voluntary participants of the field test and a control group of mountain rescuers that did not participate in the field test. Both groups included respondents from all regions. In total, 90 field test participants provided responses, of which 8 had to be 
removed from the final sample due to missing values in the core constructs. The randomly selected mountain rescuers of the control group provided 81 responses, 64 provided all answers. The final sample size of 146 rescuers exceeds the desired target size required to assess the proposed model based on statistical power analysis. In addition, we gathered data on the average age of the rescuers' population in the three regions, which closely matched the age structure represented in the sample. Sample characteristics are reported in Table 1.

Due to the study's nature of investigating the relationship between individual attitudes, perceptions and intentions, which are difficult to observe by others, the individual respondent was selected as informant for all items. Several a priori measures suggested by Podsakoff et al. (2003) were implemented to reduce the probability of common method bias. First, the respondents were assured anonymity of their responses and asked to answer honestly to reduce biases caused by social desirability. Second, the items were short, focused, and simple so that respondents did not need to think long about their answers. Third, the statements were formulated as fact-based statements (e.g. I have the resources necessary to use drones) that respondents could agree or disagree with, which are less associated with such a bias. Ex-post, we applied Harman's single-factor test to investigate potential common method variance. We performed an exploratory factor analysis, including all multi-items. The unrotated solution extracted six factors with eigenvalues greater than one and none of them accounted for the majority of variance. However, results of the Harman's test do not rule out potential common method bias entirely, which is further discussed in the limitations.

\subsection{Measurement}

We used reflective multi-item measures with seven-point Likert-type scales $(1$ - strongly disagree to 7 - strongly agree) for multivariate constructs, which are provided in the Table A1. For the main model constructs BI, PE, EE, SI, and FC, we used the original UTAUT items from Venkatesh et al. (2003), slightly adapting the items to fit the study context. Higher EE scores, for instance, express that an individual expects lower efforts (i.e. I would find
Drones to the rescue?

389

\begin{tabular}{|c|c|c|c|c|c|c|}
\hline & Number & Percentage & & Number & Percentage & \\
\hline Gender & \multicolumn{5}{|c|}{ Employment type } & \\
\hline Male & 131 & 89.7 & Voluntary & 38 & 26.0 & \\
\hline \multirow[t]{2}{*}{ Female } & 15 & 10.3 & Paid & 80 & 54.8 & \\
\hline & & & No answer & 28 & 19.2 & \\
\hline Age & & & \multicolumn{3}{|c|}{ Job tenure (years) } & \\
\hline$<21$ & 9 & 6.2 & $1-10$ & 51 & 34.9 & \\
\hline $21-30$ & 31 & 21.2 & $11-20$ & 36 & 24.7 & \\
\hline $31-40$ & 24 & 16.4 & $21-30$ & 25 & 17.1 & \\
\hline $41-50$ & 32 & 21.9 & $>30$ & 22 & 15.1 & \\
\hline$>50$ & 50 & 34.2 & No answer & 12 & 8.2 & \\
\hline \multicolumn{3}{|l|}{ Position } & \multicolumn{3}{|c|}{ Working hours (per month) } & \\
\hline Operational staff (non leading) & 62 & 42.5 & $<40$ & 41 & 28.1 & \\
\hline Operational staff (leading) & 66 & 45.2 & $40-99$ & 21 & 14.4 & \\
\hline Officials (high-ranking) & 7 & 4.8 & $100-160$ & 13 & 8.9 & \\
\hline Other & 8 & 5.5 & $>160$ & 54 & 37.0 & \\
\hline No answer & 3 & 2.1 & No answer & 17 & 11.6 & \\
\hline \multicolumn{3}{|l|}{ Drone experience } & \multicolumn{3}{|c|}{ Field test participation } & \\
\hline No & 79 & 54.1 & No & 64 & 43.8 & \\
\hline Yes & 67 & 45.9 & Yes & 82 & 56.2 & \\
\hline \multicolumn{6}{|l|}{ Note(s): $n=146$} & Sample descriptives \\
\hline
\end{tabular}


IJPDLM

51,4

drones easy to use). Experience with drones and participation in the field test were captured with dichotomous single items.

Several covariates were included to control for the effects of further individual factors that might affect the adoption of new technologies. Drawing on Venkatesh et al. (2003), we added multi-item measures to capture anxiety and attitude toward using new technologies to the model. Furthermore, we integrated job tenure (in years) and the number of rescue hours per month to capture work experience-related aspects that might affect adoption. Finally, we also controlled for gender.

\subsection{Scale properties}

We performed a set of tests to assess the validity and reliability of the applied scales. Cronbach's alpha coefficients range between 0.74 and 0.97 and are satisfactory. Composite reliability scores were calculated, which also inform about the internal consistency but are less biased toward the number of items (Netemeyer et al., 2003). With scores between 0.85 and 0.98 this measure also supports internal consistency. Next, we conducted principal component analyses with varimax rotation, including each construct's items separately to test the scales' unidimensionality (Hair et al., 2014). Each exploratory factor analysis only extracted one factor with eigenvalues greater than one and thereby demonstrated unidimensionality (Hair et al., 2014).

Next, confirmatory factor analysis (CFA) (maximum likelihood estimation), including all reflective multi-item measures was performed. All factor loadings were significant $(\phi<0.001)$ and the average variance extracted is $\geq 0.50$ for all constructs, which demonstrates convergent validity. The $\chi^{2} / \mathrm{df}$ ratio is 2.065 , the comparative fit index (CFI) is 0.91 , and the root mean square error of approximation (RMSEA) is 0.086, which are also within the boundaries recommended by $\mathrm{Hu}$ and Bentler (1998). Furthermore, discriminant validity at the indicator level is supported as the correlation of each item with its corresponding construct was greater than its correlation with the other constructs, and as cross-correlations do not exceed 0.40 . At the construct level, discriminant validity was established. The results of the square root of each latent variable's average variance extracted are greater than the highest correlation with all other constructs (Fornell and Larcker, 1981). Finally, we assessed potential multicollinearity by calculating the variance inflation factors (VIF). The scores for all variables in the model are clearly below the recommended threshold of 5 (Hair et al., 2014).

The means, standard deviations, correlations, and alpha coefficients are reported in Table 2 . The CFA results, including loadings, significance, average variance extracted and fit indices are reported along with the used reflective items in the Table A1.

\section{Results}

\subsection{Main model}

We applied ordinary least squares regression analysis with behavioral intention (BI) as the dependent variable to assess the proposed relationships. Table 3 summarizes the results.

The baseline model with the covariates (base model) shows that only the attitude toward using technology has a positive effect on BI, and the effect becomes nonsignificant once the main predictors are added in the main model. Next, the direct effects of the predictors on BI were added to the model (main model). $\mathrm{PE}(\beta=0.19 ; p=0.016), \mathrm{FC}(\beta=0.31 ; p<0.001)$, and EXP with drones $(\beta=0.32 ; p<0.001)$ have positive effects on $\mathrm{BI}$, which supports hypotheses $1,4 \mathrm{a}$, and $5 \mathrm{a}$. $\mathrm{EE}(\beta=-0.01 ; p=0.962)$, SI $(\beta=0.01 ; p=0.938)$ and $\mathrm{FT}$ participation $(\beta=0.12$; $p=0.08$ ) do not show a direct impact on BI. Therefore, hypotheses 2,3 and 6 a are rejected by the data. In total, the model explains $57 \%$ (Adj. $R^{2}=0.54$ ) in BI's variance, which is an increase of $27 \%$ from the base model, and the model fit increases significantly with the newly added predictors $(\Delta F=14.11, p<0.001)$. 


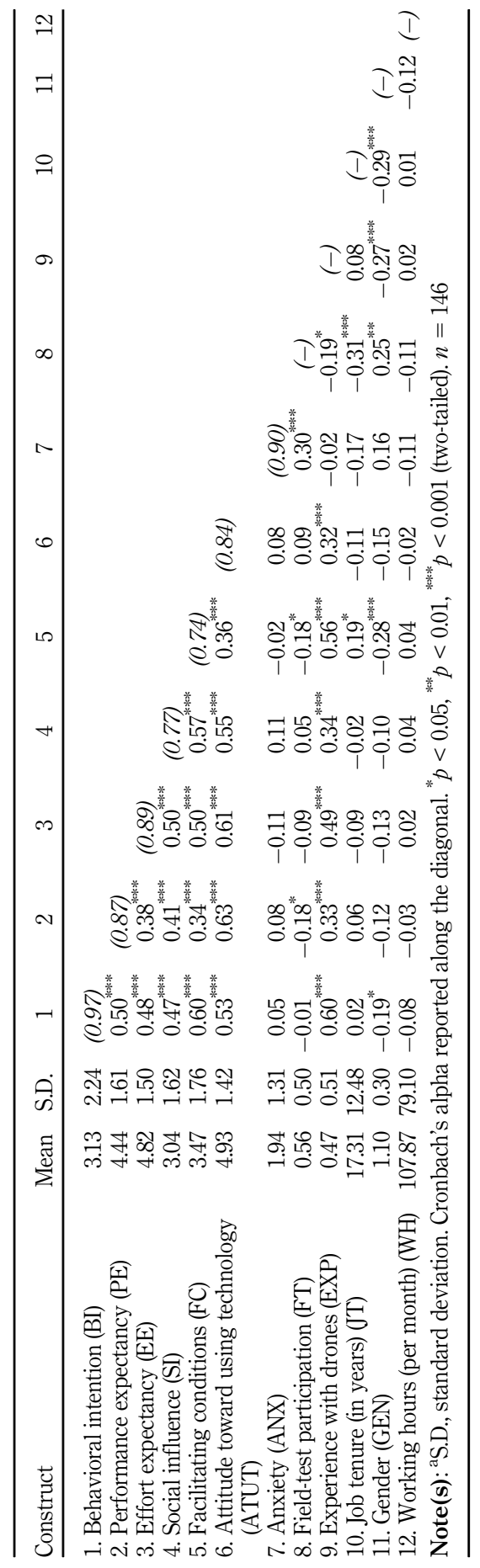

Drones to the rescue?

391

Table 2. Mean, standard deviations, and correlation matrix ${ }^{\mathrm{a}}$ 
IJPDLM
51,4

392
Table 3

Results of OLS-

Regression models ${ }^{\mathrm{a}}$




Ex post analysis of the main model shows that multicollinearity is not an issue (highest $\mathrm{VIF}=2.71$ ), and the normal distribution of the residual of the regression variate (skewness $=0.201$; kurtosis $=0.399$; Shapiro-Wilk Test $p=0.303$ ) supports the notion that the regression results can be meaningfully interpreted.

\subsection{Moderation effects}

To test the proposed moderation hypotheses, we extended the main model by integrating interaction terms for each of the proposed moderation effects. The interaction terms were calculated based on the mean-centered variable scores to allow for meaningful interpretation of the results (Aiken et al., 1991). Therefore, the single-item score of FT and EXP with drones and the construct score of $\mathrm{FC}$ were multiplied with the construct scores of $\mathrm{PE}$ and $\mathrm{EE}$, resulting in the required six interaction terms. The moderation analyses were performed separately for each moderator to prevent potential multicollinearity issues. The results are summarized in Table 3 in moderation models 1 to 3 .

When adding the two interaction terms in moderation model 1 to assess the moderating effects of FT participation, the effects of the main model remain the same, but no interaction effect is significant and neither explained variance nor model fit changed. Thus, hypotheses $6 \mathrm{~b}$ and $6 \mathrm{c}$ are rejected by the data. In moderation model 2 , we investigated the moderation effect of EXP with drones. While the effects of the main model are similar, the interaction term testing whether the PE-BI relationship is contingent upon the EXP with drones is positive and significant $(\beta=0.16 ; p=0.012)$. The EE-BI relationship is not moderated by EXP $(\beta=0.06 ; p=0.349)$. Thus, the empirical data support hypothesis $5 \mathrm{~b}$ but reject $5 \mathrm{c}$. The identified moderation term explains $3 \%$ in additional variance in BI and the model fit increases significantly $(\Delta F=4.34, p<0.015)$. Moderation model 3 investigates the contingency effect of $\mathrm{FC}$. The PE-BI relationship is contingent upon $\mathrm{FC}$ is positive and significant $(\beta=0.17 ; p=0.007)$. However, the $\mathrm{EE}-\mathrm{BI}$ relationship is not moderated by $\mathrm{FC}$ $(\beta=-0.01 ; p=0.923)$. The significant moderation explained $2 \%$ in additional variance in $\mathrm{BI}$ and the model fit increases significantly $(\Delta F=3.90, p<0.023)$. Thus, the data support hypothesis $4 \mathrm{~b}$ but reject $4 \mathrm{c}$.

Figure 2 depicts the plots of the simple slope analyses to graphically illustrate the strength of PE's effect on BI regarding the low (mean minus one standard deviation) and high (mean plus one standard deviation) moderator levels of the two significant moderation effects.
Drones to the rescue?
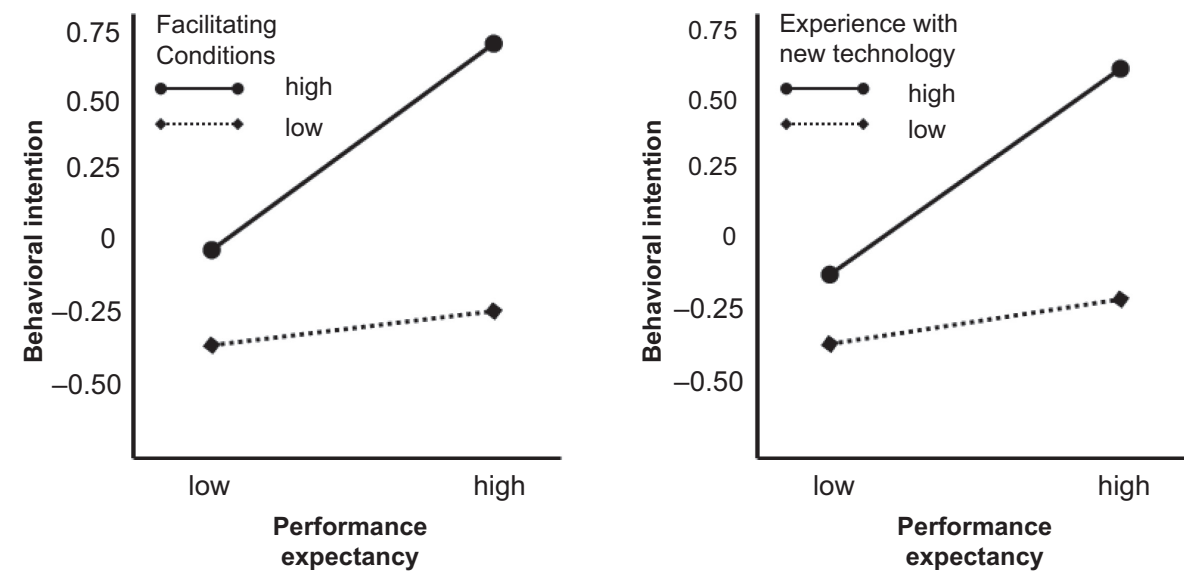

Figure 2.

Plots of the simple slope analyses 
IJPDLM 51,4

\section{Discussion and conclusions}

\subsection{Theoretical implications}

This the first study shedding light on the determinants that influence mountain rescuers' behavioral intention to use drones. We developed a framework that presents novel insights on personal and environment-related factors influencing the adoption of new technology to save lives. We add to the emerging stream of research on drone use in emergency logistics. Previous research primarily discussed drones' potential contributions to increase logistics performance (Thiels et al., 2015; Tatham et al., 2017; Wankmüller et al., 2020), neglecting that these advantages can only be achieved if the technology is actually adopted. Only recently, scholars called for intensified research on the drivers of drone acceptance for logistics purposes (Boucher, 2016; Lidynia et al., 2017). We complement and extend existing knowledge by revealing the relevant determinants that facilitate adoption.

Our results confirm the relevance of performance expectancy for technology acceptance. This implies that rescuers' beliefs to being able to increase their operational performance through drones are critical. Mountain rescuers primarily aim to save lives, but they regularly face major challenges, as rescue operations require fast response times, quick decisions under uncertain conditions and targeted cooperation to rescue people in distress effectively. Technology that contributes to mitigating these challenges and improves performance is thus appreciated. Increased performance can also be associated with a lower risk of being injured and being in control of the situation (Subramaniam et al., 2012), which can further encourage adoption.

Effort expectancy was not significant, indicating that it is not important for mountain rescuers' behavioral intention to use drones even if associated with less effort. This finding contradicts the theoretical considerations (Venkatesh et al., 2003), but it is consistent with previous results on firefighters applying new technology for emergency medical service (Chen and Lin, 2019). Mountain rescuers aim at saving lives and the required effort appears subordinate and accepted. Furthermore, rescuers regularly apply a broad set of assistive technologies, resulting in an overall high level of technological understanding that may ease the adoption. We thus argue for a reconsideration of the role of effort expectancy in life saving contexts.

Our results indicate that social influence seems to have no significant effect on the behavioral intention to adopt new technology in lifesaving contexts. This finding is not consistent with the original UTAUT (Venkatesh et al., 2003), which only concluded that social influence might be less relevant in voluntary settings. In rescue missions, supporting technologies must increase operational performance, personal attitudes, and preferences might be secondary. Thus, mountain rescuers opinion on a new technology may depend primarily on its performance and is not influenced by the opinion of peers. This underlines that the technology used is secondary in rescue missions. Personality dispositions potentially provide a further explanation for the nonsignificance of social influence, as rescuers score high in extraversion (Wagner et al., 2009) and are assumed to develop their own strong opinions on technology independent of others.

The results reveal that facilitating conditions positively influence behavioral intention, indicating that rescuers who perceive their rescue organization as supportive in introducing drones have a stronger intention to adopt. The provision of necessary resources, knowledge, support, and training ease the development of own capabilities. Drones and their control are complex and operational performance gains can only be realized if they are used appropriately. This requires intensive training, otherwise drones may not increase performance or even be harmful. Our findings underline the crucial role of facilitating conditions for building behavioral intention to adopt novel technology (Venkatesh et al., 2012).

Experience has a significant direct positive influence on the behavioral intention to adopt drones. Experience enables the effective application of capabilities even in emergency 
situations (Ford and Schmidt, 2000), thus, increasing operational performance and reducing risk. Practical experience with drones can increase self-efficacy and can help to assess the performance of drones more accurately. Demonstrations (field test) as observations of the operational benefits appear to be not suitable to trigger intention. Performance demonstrations might be intimidating for rescuers, in particular for inexperienced rescuers. Field tests are often designed to demonstrate the maximum performance. However, this might cause apprehensions of not being able to use the technology to its full potential. Indeed, field test participants have higher anxiety scores than other rescuers.

Besides our contributions to the emergency logistics literature, we also add to the extant literature on technology acceptance, particularly in rescue and live-saving contexts. In contrast to the theoretical assumptions (Venkatesh et al., 2003), our results indicate that the role of effort expectancy and social influence seems to be less critical in such contexts and may need to be revisited. We provide empirical evidence that when rescuing people is the ultimate goal performance expectancy and facilitating conditions are the primary drivers of intention to adopt. Specifically, our results suggest that facilitating conditions that have so far received less attention play a central role as they directly affect the behavioral intention and appear to be also moderating the performance expectancy-intention relationship. We further contribute to the literature by proposing that the role of prior experience may needs to be extended as our results show that experience has a direct effect on behavioral intention. Prior research considered experience only to be a relevant moderator (Venkatesh $\mathrm{et}$ al., 2003). Our results add to existing knowledge by revealing that prior drone experience also moderates the relationship between performance expectancy and behavioral intention as the effect of performance expectancy becomes stronger for experienced mountain rescuers. These findings emphasize the importance of prior technological experiences by highlighting that these experiences exert direct and indirect effects on behavioral intention. Furthermore, we contribute to a more nuanced understanding of the relevance of prior experiences for new technology acceptance by differentiating between own experiences and demonstrations via field tests by highlighting that the latter appears to be not sufficient to drive behavioral intention.

\subsection{Practical implications}

Drones are expected to provide crucial operational performance gains in mountain rescue missions, but the technology is currently not widely used. Drone manufacturers can draw on our results to facilitate adoption in rescue contexts by focusing on three central aspects: (1) operational performance is of paramount importance. Manufacturers are thus advised to point out the existing performance benefits clearly and strive for further improvements; (2) support rescue organizations in drone implementation. Special trainings, education, and the provision of test material can contribute to establishing favorable facilitating conditions; (3) actively promote personal drone experience.

Rescue organizations are advised to design drone trainings in accordance with the $a$ priori communicated performance expectations of rescuers. Instructors should openly address drone performance and the efforts required to enable accurate assessments. Further, comprehensive guidelines for rescuers that contain precise information on drones' performance and limitations are needed. Standard mission protocols that allow rescuers detailed documentation of drone usage may further ease adoption.

\subsection{Limitations and future research}

This study has limitations that arise due to the study's novelty and context-specific issues concerning the sample but potentially pave the way for future research. There is no public register of mountain rescuers available. The selection of respondents might not be fully random, and potential self-selection bias could not be avoided systematically. Drones are not 
IJPDLM 51,4

widely implemented in mountain rescue missions. Thus, our study emphasized the frontend of the adoption process by investigating the behavioral intention to use drones in future. Even though prior research confirmed that intention is the closest proxy for actual use, future research should clarify whether this also applies in this context. Further, this study uses data obtained from a single-informant survey, which has been explained to be driven by the investigated relationships between attitudes, perceptions, and intentions of the individual. Although we took several measures to reduce potential common method bias, this bias could still not be ruled out entirely. Future research might apply a longitudinal design and assess actual and thereby observable adoption behavior instead of adoption intention as the dependent variable to overcome this issue.

Experience with drones was measured using a dichotomous variable. As a result, we can only report that experience positively affects the adoption intention. However, we are unable to determine whether more experience also leads to a higher adoption propensity or if more experience will eventually be detrimental. Future research could further investigate this relationship. The sample is restricted to mountain rescuers in the European Alps. We assume that these determinants are not specific to this region, but we cannot completely preclude a regional or cultural influence that provides an opportunity for future research. Further, the number of female respondents in our sample is limited. Even though this corresponds to the small number of female mountain rescuers, it prevents the further investigation of potential gender differences. Future research is thus advised to strive for more gender-balanced samples.

\section{References}

Aiken, L.S., West, S.G. and Reno, R.R. (1991), Multiple Regression: Testing and Interpreting Interactions, Sage Publications, New York.

Ajzen, I. (1991), "The theory of planned behavior", Organizational Behavior and Human Decision Processes, Vol. 50 No. 2, pp. 179-211.

Ajzen, I. and Fishbein, M. (2005), “The influence of attitudes on behavior”, in Al-barracin, D., Johnson, B.T. and Zanna, M.P. (Eds), The Handbook of Attitudes, pp. 173-221.

Anbaroğlu, B. (2019), "Drones in healthcare: an extended discussion on humanitarian logistics", Unmanned Aerial Vehicles in Civilian Logistics and Supply Chain Management, IGI Global, pp. 86-114.

Apollo, M. (2017), "The true accessibility of mountaineering: the case of the High Himalaya”, Journal of Outdoor Recreation and Tourism, Vol. 17, pp. 29-43.

Baer, W.S., Johnson, L.L. and Merrow, E.W. (1977), "Government-sponsored demonstrations of new technologies”, Science, Vol. 196 No. 4293, pp. 950-957.

Balasingam, M. (2017), "Drones in medicine-the rise of the machines", International Journal of Clinical Practice, Vol. 71 No. 9, pp. 1-4.

Bergrettung Tirol (2019), "ITAT3023 - START. Smart test alpiner Rettungstechnik \& -technologie", available at: https://bergrettung.tirol/php/interreg,1411.html.

Blancher, M., Albasini, F., Elsensohn, F., Zafren, K., Hölzl, N., McLaughlin, K., Wheeler, A.R. III, Roy, S., Brugger, H. and Greene, M. (2018), "Management of multi-casualty incidents in mountain rescue: evidence-based guidelines of the international commission for mountain emergency medicine (ICAR MEDCOM)", High Altitude Medicine and Biology, Vol. 19 No. 2, pp. 131-140.

Boucher, P. (2016), “You wouldn't have your granny using them': drawing boundaries between acceptable and unacceptable applications of civil drones", Science and Engineering Ethics, Vol. 22 No. 5, pp. 1391-1418.

Cacace, J., Finzi, A., Lippiello, V., Furci, M., Mimmo, N. and Marconi, L. (2016), “A control architecture for multiple drones operated via multimodal interaction in search \& rescue mission", 2016 
IEEE International Symposium on Safety, Security, and Rescue Robotics (SSRR), Lausanne, 2016, pp. 233-239.

Câmara, D. (2014), "Cavalry to the rescue: drones fleet to help rescuers operations over disasters scenarios", IEEE Conference on Antenna Measurements \& Applications (CAMA), pp. 1-4.

Chen, Y.-C. and Lin, S.-K. (2019), "Intention to apply mobile device in emergency medical service sites for fire fighters", Procedia Manufacturing, Vol. 30, pp. 357-364.

Ciesa, M., Grigolato, S. and Cavalli, R. (2014), "Analysis on vehicle and walking speeds of search and rescue ground crews in mountainous areas", Journal of Outdoor Recreation and Tourism, Vol. 5, pp. 48-57.

Cohen, J. (1992), “A power primer”, Psychological Bulletin, Vol. 112 No. 1, p. 155.

Cui, J.Q., Phang, S.K., Ang, K.Z.Y., Wang, F., Dong, X., Ke, Y., Lai, S., Li, K., Li, X., Lin, F. and others (2015), "Drones for cooperative search and rescue in post-disaster situation", IEEE 2015 - 2015 IEEE 7th International Conference, pp. 167-174.

Davis, F.D. (1989), "Perceived usefulness, perceived ease of use, and user acceptance of information technology”, MIS Quarterly, Vol. 13 No. 3, pp. 319-340.

Davis, F.D., Bagozzi, R.P. and Warshaw, P.R. (1989), "User acceptance of computer technology: a comparison of two theoretical models", Management Science, Vol. 35 No. 8, pp. 982-1003.

Doherty, P. and Rudol, P. (2007), "A UAV search and rescue scenario with human body detection and geolocalization”, Australasian Joint Conference on Artificial, Springer, 2007, pp. 1-13.

Fishbein, M. and Ajzen, I. (1975), Belief, Attitude, Intention, and Behavior: An Introduction to Theory and Research, Addison-Wesley, Reading.

Ford, J.K. and Schmidt, A.M. (2000), "Emergency response training: strategies for enhancing realworld performance", Journal of Hazardous Materials, Vol. 75 Nos 2-3, pp. 195-215.

Fornell, C. and Larcker, D.F. (1981), "Evaluating structural equation models with unobservable variables and measurement error", Journal of Marketing Research, Vol. 18 No. 1, pp. 39-50.

Hair, J.F., Black, W.C., Babin, B.J. and Anderson, R.E. (2014), Multivariate Data Analysis, Pearson New International Edition, Pearson Education, Essex.

Halassi, S., Semeijn, J. and Kiratli, N. (2019), "From consumer to prosumer: a supply chain revolution in 3D printing”, International Journal of Physical Distribution and Logistics Management, Vol. 49 No. 2, pp. 200-216.

Hamilton, R.W. and Thompson, D.V. (2007), "Is there a substitute for direct experience? Comparing consumers' preferences after direct and indirect product experiences”, Journal of Consumer Research, Vol. 34 No. 4, pp. 546-555.

Hayajneh, A.M., Zaidi, S.A.R., Des McLernon, C., Di Renzo, M. and Ghogho, M. (2018), "Performance analysis of uav enabled disaster recovery networks: a stochastic geometric framework based on cluster processes”, IEEE Access, Vol. 6, pp. 26215-26230.

Heggie, T.W. (2008), "Search and rescue in Alaska's national parks", Travel Medicine and Infectious Disease, Vol. 6 No. 6, pp. 355-361.

Hermanns, A. (2013), Anwender-Akzeptanz und Bewertung unbemannter Flugsysteme ("Drohnen") im Katastrophenschutz: Theorie, Empirie, regulatorische Implikationen, LIT Verlag Münster, Berlin.

Holzmann, P., Schwarz, E.J. and Audretsch, D.B. (2020), "Understanding the determinants of novel technology adoption among teachers: the case of 3D printing", The Journal of Technology Transfer, Vol. 45 No. 1, pp. 259-275.

Hu, L.-t. and Bentler, P.M. (1998), "Fit indices in covariance structure modeling: sensitivity to underparameterized model misspecification”, Psychological Methods, Vol. 3 No. 4, p. 424.

ICAR (2019), "ICAR 2019 convention / highlights videos", available at: http://www.alpine-rescue.org/ xCMS5/WebObjects/nexus5.woa/wa/icar?menuid =1094\&rubricid=255\&articleid=13141. 
IJPDLM 51,4

Kakaes, K., Greenwood, F., Lippincott, M., Dosemagen, S., Meier, P. and Wich, S. (2015), Drones and Aerial Observation: New Technologies for Property Rights, Human Rights, and Global Development: A Primer, New America, Washington, pp. 6-103.

Kapser, S. and Abdelrahman, M. (2020), "Acceptance of autonomous delivery vehicles for last-mile delivery in Germany-Extending UTAUT2 with risk perceptions", Transportation Research Part C: Emerging Technologies, Vol. 111, pp. 210-225.

Karaca, Y., Cicek, M., Tatli, O., Sahin, A., Pasli, S., Beser, M.F. and Turedi, S. (2018), "The potential use of unmanned aircraft systems (drones) in mountain search and rescue operations", The American Journal of Emergency Medicine, Vol. 36 No. 4, pp. 583-588.

Karak, A. and Abdelghany, K. (2019), "The hybrid vehicle-drone routing problem for pick-up and delivery services", Transportation Research Part C: Emerging Technologies, Vol. 102, pp. 427-449.

Khan, R., Tausif, S. and Javed Malik, A. (2019), "Consumer acceptance of delivery drones in urban areas", International Journal of Consumer Studies, Vol. 43 No. 1, pp. 87-101.

Kharb, L. (2015), "Moving ahead in future with drones: the UAV's (unmanned aerial vehicle)", Journal of Network Communications and Emerging Technologies (JNCET), Vol. 4 No. 3, pp. 21-23.

Kim, K.-B. and Chung, B.-G. (2019), "Technology acceptance of industry 4.0 applying UTAUT2: focusing on AR and drone services", Journal of Information Technology Applications and Management, Vol. 26 No. 6, pp. 29-46.

Kiss Leizer, G.K. (2018), "Possible areas of application of drones in waste management during rail accidents and disasters", Interdisciplinary Description of Complex Systems: INDECS, Vol. 16 No. 3-A, pp. 360-368.

Kwee-Meier, S.T., Bützler, J.E. and Schlick, C. (2016), "Development and validation of a technology acceptance model for safety-enhancing, wearable locating systems", Behaviour and Information Technology, Vol. 35 No. 5, pp. 394-409.

Lidynia, C., Philipsen, R. and Ziefle, M. (2017), "Droning on about drones-acceptance of and perceived barriers to drones in civil usage contexts", Advances in Human Factors in Robots and Unmanned Systems, Springer, pp. 317-329.

Lischke, V., Byhahn, C., Westphal, K. and Kessler, P. (2001), "Mountaineering accidents in the European Alps: have the numbers increased in recent years?", Wilderness and Environmental Medicine, Vol. 12 No. 2, pp. 74-80.

Liu, R., Ding, Z., Jiang, X., Sun, J., Jiang, Y. and Qiang, W. (2020), "How does experience impact the adoption willingness of battery electric vehicles? The role of psychological factors", Environmental Science and Pollution Research, pp. 1-18.

Mangiaracina, R., Perego, A., Seghezzi, A. and Tumino, A. (2019), "Innovative solutions to increase last-mile delivery efficiency in B2C e-commerce: a literature review", International Journal of Physical Distribution and Logistics Management, Vol. 49 No. 9, pp. 901-920.

Mathieson, K. (1991), "Predicting user intentions: comparing the technology acceptance model with the theory of planned behavior", Information Systems Research, Vol. 2 No. 3, pp. 173-191.

McRae, J.N., Gay, C.J., Nielsen, B.M. and Hunt, A.P. (2019), "Using an unmanned aircraft system (drone) to conduct a complex high altitude search and rescue operation: a case study", Wilderness and Environmental Medicine, Vol. 30 No. 3, pp. 287-290.

Moore, G.C. and Benbasat, I. (1991), "Development of an instrument to measure the perceptions of adopting an information technology innovation", Information Systems Research, Vol. 2 No. 3, pp. 192-222.

Mort, A. and Godden, D. (2011), "Injuries to individuals participating in mountain and wilderness sports: a review", Clinical Journal of Sport Medicine, Vol. 21 No. 6, pp. 530-536.

Muhar, A., Schauppenlehner, T., Brandenburg, C. and Arnberger, A. (2007), "Alpine summer tourism: the mountaineers' perspective and consequences for tourism strategies in Austria", Forest Snow and Landscape Research, Vol. 81 No. 7, pp. 7-17. 
Netemeyer, R.G., Bearden, W.O. and Sharma, S. (2003), Scaling Procedures: Issues and Applications, Sage Publications.

Nordhoff, S., Louw, T., Innamaa, S., Lehtonen, E., Beuster, A., Torrao, G., Bjorvatn, A., Kessel, T., Malin, F., Happee, R. and Merat, N. (2020), "Using the UTAUT2 model to explain public acceptance of conditionally automated (L3) cars: a questionnaire study among 9,118 car drivers from eight European countries", Transportation Research Part F: Traffic Psychology and Behaviour, Vol. 74, pp. 280-297.

Pietsch, U., Strapazzon, G., Ambühl, D., Lischke, V., Rauch, S. and Knapp, J. (2019), "Challenges of helicopter mountain rescue missions by human external cargo: need for physicians onsite and comprehensive training", Scandinavian Journal of Trauma, Resuscitation and Emergency Medicine, Vol. 27 No. 1, pp. 1-7.

Plouffe, C.R., Vandenbosch, M. and Hulland, J. (2001), "Intermediating technologies and multi-group adoption: a comparison of consumer and merchant adoption intentions toward a new electronic payment system", Journal of Product Innovation Management, Vol. 18 No. 2, pp. 65-81.

Podsakoff, P.M., MacKenzie, S.B., Lee, J.-Y. and Podsakoff, N.P. (2003), "Common method biases in behavioral research: a critical review of the literature and recommended remedies", Journal of Applied Psychology, Vol. 88 No. 5, pp. 879-903.

Rabta, B., Wankmüller, C. and Reiner, G. (2018), "A drone fleet model for last-mile distribution in disaster relief operations", International Journal of Disaster Risk Reduction, Vol. 28, pp. 107-112.

Ramadan, Z.B., Farah, M.F. and Mrad, M. (2017), "An adapted TPB approach to consumers' acceptance of service-delivery drones”, Technology Analysis and Strategic Management, Vol. 29 No. 7, pp. 817-828.

Rogers, E.M. (2010), Diffusion of Innovations, Simon and Schuster, New York.

Sanfridsson, J., Sparrevik, J., Hollenberg, J., Nordberg, P., Djärv, T., Ringh, M., Svensson, L., Forsberg, S., Nord, A., Andersson-Hagiwara, M. and Claesson, A. (2019), "Drone delivery of an automated external defibrillator - a mixed method simulation study of bystander experience", Scandinavian Journal of Trauma, Resuscitation and Emergency Medicine, Vol. 27 No. 1, p. 40.

Schaafstal, A.M., Johnston, J.H. and Oser, R.L. (2001), “Training teams for emergency management", Computers in Human Behavior, Vol. 17 Nos 5-6, pp. 615-626.

Shimansky, C. (2008), Accidents in Mountain Rescue Operation, Mountain Rescue Association Evergreen, Colorado.

Silvagni, M., Tonoli, A., Zenerino, E. and Chiaberge, M. (2017), "Multipurpose UAV for search and rescue operations in mountain avalanche events", Geomatics, Natural Hazards and Risk, Vol. 8 No. 1, pp. 18-33.

Škrinjar, J.P., Škorput, P. and Furdić, M. (2018), Application of Unmanned Aerial Vehicles in Logistic Processes, Springer 2018 - International Conference New Technologies, pp. 359-366.

Subramaniam, C., Ali, H. and Mohd Shamsudin, F. (2012), "Initial emergency response performance of fire fighters in Malaysia", International Journal of Public Sector Management, Vol. 25 No. 1, pp. 64-73.

Sun, Y., Wang, N., Guo, X. and Peng, Z. (2013), "Understanding the acceptance of mobile health services: a comparison and integration of alternative models", Journal of Electronic Commerce Research, Vol. 14 No. 2, pp. 183-200.

Tatham, P., Stadler, F., Murray, A. and Shaban, R.Z. (2017), "Flying maggots: a smart logistic solution to an enduring medical challenge", Journal of Humanitarian Logistics and Supply Chain Management, Vol. 7 No. 2, pp. 172-193.

Thiels, C.A., Aho, J.M., Zietlow, S.P. and Jenkins, D.H. (2015), "Use of unmanned aerial vehicles for medical product transport", Air Medical Journal, Vol. 34 No. 2, pp. 104-108.

van Tilburg, C. (2017), "First report of using portable unmanned aircraft systems (drones) for search and rescue", Wilderness and Environmental Medicine, Vol. 28 No. 2, pp. 116-118. 
IJPDLM

51,4
Venkatesh, V., Morris, M.G., Davis, G.B. and Davis, F.D. (2003), "User acceptance of information technology: toward a unified view", MIS Quarterly, pp. 425-478.

Venkatesh, V., Thong, J.Y.L. and Xu, X. (2012), "Consumer acceptance and use of information technology: extending the unified theory of acceptance and use of technology", MIS Quarterly, pp. 157-178.

Wagner, S.L., Martin, C.A. and McFee, J.A. (2009), "Investigating the "rescue personality"”, Traumatology, Vol. 15 No. 3, pp. 5-12.

Wankmüller, C., Truden, C., Korzen, C., Hungerländer, P., Kolesnik, E. and Reiner, G. (2020), "Optimal allocation of defibrillator drones in mountainous regions", OR Spectrum, Vol. 2 No. 1, p. 86.

Yarwood, R. (2010), "Risk, rescue and emergency services: the changing spatialities of mountain rescue teams in England and Wales", Geoforum, Vol. 41 No. 2, pp. 257-270. 


\begin{tabular}{|c|c|c|c|c|c|}
\hline \multirow{4}{*}{$\begin{array}{l}\text { Construct/source } \\
\text { Behavioral intention } \\
\text { Source: Venkatesh et al. } \\
\text { (2003) }\end{array}$} & \multirow{2}{*}{ Items } & \multicolumn{2}{|c|}{$\begin{array}{l}\text { Factor } \\
\text { loading }\end{array}$} & \multirow{2}{*}{$\frac{\mathrm{AVE}}{0.93}$} & \multirow[b]{2}{*}{401} \\
\hline & & 0.97 & **** & & \\
\hline & I predict I would use drones in the next 6 months & 0.96 & $* * *$ & \multirow{5}{*}{0.68} & \\
\hline & & 0.96 & **** & & \\
\hline \multirow{4}{*}{$\begin{array}{l}\text { Performance expectancy } \\
\text { Source: Venkatesh } \text { et al. } \\
\text { (2003) }\end{array}$} & & & & & \\
\hline & I would find drones useful in my job & 0.88 & **** & & \\
\hline & Drones enable me to accomplish tasks more quickly & 0.80 & $* * *$ & & \\
\hline & Drones increase my productivity & 0.80 & **** & \multirow{3}{*}{0.70} & \\
\hline \multirow{5}{*}{$\begin{array}{l}\text { Effort expectancy } \\
\text { Source: Venkatesh et al. } \\
\text { (2003) }\end{array}$} & & & & & \\
\hline & $\begin{array}{l}\text { My interaction with drones would be clear and } \\
\text { understandable }\end{array}$ & 0.64 & **** & & \\
\hline & It would be easy for me to become skillful at using drones & 0.86 & **** & \multirow{6}{*}{0.62} & \\
\hline & I would find drones easy to use & 0.94 & $* * *$ & & \\
\hline & Learning to operate drones is easy for me & 0.86 & $* * *$ & & \\
\hline \multirow{4}{*}{$\begin{array}{l}\text { Social influence } \\
\text { Source: Venkatesh et al. } \\
\text { (2003) }\end{array}$} & & & & & \\
\hline & $\begin{array}{l}\text { People who influence my behavior think that I should use } \\
\text { drones }\end{array}$ & 0.88 & **** & & \\
\hline & $\begin{array}{l}\text { People who are important to me think that I should use } \\
\text { drones }\end{array}$ & 0.88 & $* * * *$ & & \\
\hline & $\begin{array}{l}\text { The head of operations in my organization has been helpful } \\
\text { in the use of drones }\end{array}$ & 0.47 & **** & & \\
\hline \multirow{4}{*}{$\begin{array}{l}\text { Facilitating conditions } \\
\text { Source: Venkatesh et al. } \\
\text { (2003) }\end{array}$} & & & & \multirow[t]{4}{*}{0.50} & \\
\hline & I have the resources necessary to use drones & 0.72 & **** & & \\
\hline & I have the knowledge $\mathrm{n}$ & 0.85 & $* * *$ & & \\
\hline & $\begin{array}{l}\text { A specific person (or group) is available for assistance with } \\
\text { drone difficulties }\end{array}$ & 0.49 & $* * *$ & & \\
\hline \multirow{5}{*}{$\begin{array}{l}\text { Anxiety } \\
\text { Source: Venkatesh et al. } \\
\text { (2003) }\end{array}$} & & & & \multirow[t]{5}{*}{0.69} & \\
\hline & I feel apprehensive about using drones & 0.81 & $* * *$ & & \\
\hline & $\begin{array}{l}\text { It scares me to think I could crash the drone by pressing a } \\
\text { wrong button }\end{array}$ & 0.84 & $* * *$ & & \\
\hline & $\begin{array}{l}\text { I hesitate to use drones for fear of making mistakes I cannot } \\
\text { correct }\end{array}$ & 0.84 & **** & & \\
\hline & Drones are somewhat intimidating to me & 0.83 & $* * *$ & & \\
\hline \multicolumn{2}{|c|}{ Attitude toward using technology } & & & \multirow[t]{5}{*}{0.62} & \multirow{5}{*}{$\begin{array}{r}\text { Table A1. } \\
\text { Measures, factor } \\
\text { loadings, and }\end{array}$} \\
\hline \multirow{4}{*}{$\begin{array}{l}\text { Source: Venkatesh } \text { et al. } \\
\text { (2003) }\end{array}$} & I like working with drones & 0.97 & $* * *$ & & \\
\hline & Drones make work more interesting & 0.72 & **** & & \\
\hline & Working with drones is fun & 0.89 & $* * *$ & & \\
\hline & Using drones is a good idea & 0.47 & **** & & \\
\hline \multicolumn{6}{|c|}{ 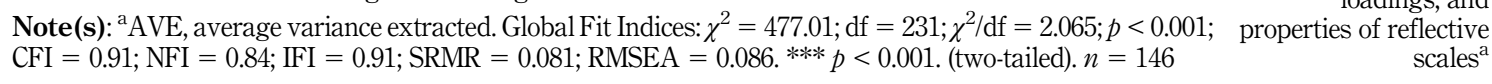 } \\
\hline
\end{tabular}

\section{About the authors}

Patrick Holzmann is the vice head of the Department of Innovation Management and Entrepreneurship at the University of Klagenfurt, Austria. He holds a $\mathrm{PhD}$ in Social and Economic Sciences in the field of entrepreneurship and innovation management. His research interests include business models, novel technology adoption, digitalization and sustainability. His work is published in journals such as Technological Forecasting and Social Change, Journal of Technology Transfer and Journal of Cleaner Production. Patrick Holzmann is the corresponding author and can be contacted at: patrick.holzmann@aau.at 
IJPDLM 51,4
Christian Wankmüller is a postdoctoral assistant in the Department of Operations, Energy and Environmental Management at the University of Klagenfurt (Austria). Currently, he is vice head of the department. He received his doctoral degree from the University of Klagenfurt in 2018. His main focus of research is put on humanitarian logistics, disaster management processes and sustainable supply chain management. In his research work Christian applies simulation modeling, e.g. system dynamics, discrete-event simulation and agent-based modeling and qualitative methods including case study research.

Dietfried Globocnik works as senior scientist at the University of Klagenfurt and the University of Graz. He holds a diploma in business administration and a doctorate in social and economic sciences from the University of Graz. His research interest entails innovation marketing, corporate entrepreneurship and organizing innovation activities in MNEs. His academic work is published in books and journals such as Journal of Product Innovation Management, Technovation and European Management Journal.

Erich J. Schwarz is a professor and the dean of the School of Management and Economics at the University of Klagenfurt, Austria and the Head of the Department of Innovation Management and Entrepreneurship. He received his $\mathrm{PhD}$ in the field of Economic Engineering at Technical University of Graz and his State Doctorate for Business Management at University of Graz. His research interests are in the field of entrepreneurship, innovation management and technology management.

For instructions on how to order reprints of this article, please visit our website: 